University of South Carolina

Scholar Commons

$11-7-2014$

\title{
Synthesis and Formation Mechanism of CulnS 2 Nanocrystals with a Tunable Phase
}

\author{
Chao Yu \\ Linlin Zhang \\ Long Tian \\ Dan Liu \\ Fanglin Chen \\ University of South Carolina - Columbia, chenfa@cec.sc.edu
}

See next page for additional authors

Follow this and additional works at: https://scholarcommons.sc.edu/emec_facpub

Part of the Applied Mechanics Commons, and the Inorganic Chemistry Commons

\section{Publication Info \\ Published in CrystEngComm, Volume 16, Issue 481, 2014, pages 9596-9602. \\ (C) CrystEngComm 2014, Royal Society of Chemistry.}

This article cannot be redistributed or further made available.

This article was first published by the Royal Society of Chemistry and can be found at http://dx.doi.org/ 10.1039/C4CE00893F

Yu, C., Zhang, L., Tian, L., Liu, D., Chen, F., \& Wang, C. (7 November 2014). Synthesis and Formation Mechanism of CulnS 2 Nanocrystals with a Tunable Phase. CrystEngComm, 16 (41), 9596 - 9602.

http://dx.doi.org/10.1039/C4CE00893F

This Article is brought to you by the Mechanical Engineering, Department of at Scholar Commons. It has been accepted for inclusion in Faculty Publications by an authorized administrator of Scholar Commons. For more information, please contact digres@mailbox.sc.edu. 
Author(s)

Chao Yu, Linlin Zhang, Long Tian, Dan Liu, Fanglin Chen, and Cheng Wang 


\section{CrystEngComm}
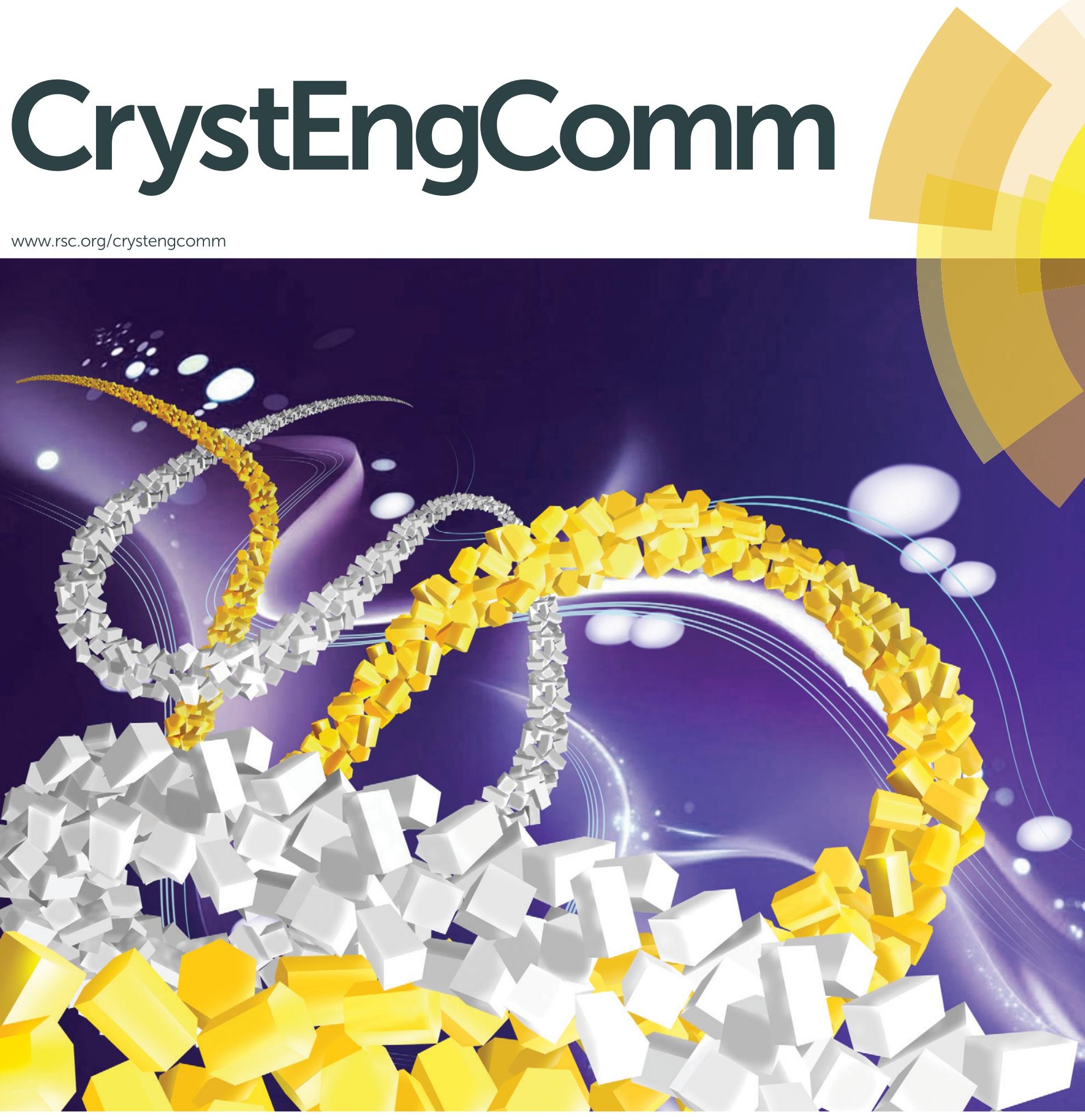


\title{
CrystEngComm
}

Cite this: CrystEngComm, 2014, 16, 9596

Received 28th April 2014, Accepted 5th June 2014

DOI: $10.1039 / c 4 c e 00893 f$

www.rsc.org/crystengcomm

\section{Synthesis and formation mechanism of $\mathrm{CulnS}_{2}$ nanocrystals with a tunable phase $\uparrow$}

\author{
Chao Yu, ${ }^{\text {ab }}$ Linlin Zhang, ${ }^{\text {ac }}$ Long Tian, ${ }^{a}$ Dan Liu, ${ }^{a}$ Fanglin Chen*d and Cheng Wang*a
}

Chalcopyrite CulnS 2 (CIS) hierarchical structures composed of nanoflakes with a thickness of about $5 \mathrm{~nm}$ were synthesized by a facial solvothermal method. The thermodynamically metastable wurtzite phase CIS would be obtained by using $\operatorname{lnCl} 3$ instead of $\operatorname{In}\left(\mathrm{NO}_{3}\right)_{3}$ as In precursor. The effects of the In precursor and the volume of concentrated $\mathrm{HCl}$ aqueous solution on the phases and morphologies of $\mathrm{CIS}$ nanocrystals have been systematically investigated. Experimental results indicated that the obtained phases of $\mathrm{CIS}$ nanocrystals were predominantly determined by precursor-induced intermediate products. The photocatalytic properties of chalcopyrite and wurtzite CIS in visible-light-driven degradation of organic dye were also compared.

\section{Introduction}

Semiconductor nanocrystals are tiny crystalline particles that exhibit size-dependent optical and electrical properties. ${ }^{1-5}$ Among the compound semiconductors, direct bandgap $\mathrm{CuInS}_{2}$ (CIS), which has a large optical absorption coefficient $\left(>10^{5} \mathrm{~cm}^{-1}\right)$ and desirable bandgap $(\sim 1.5 \mathrm{eV})$ matching well with solar spectra, is a promising semiconductor for photovoltaic devices and other optoelectronic applications. ${ }^{6}$

There are three crystalline phases, e.g., chalcopyrite, wurtzite and zinc blende for CIS. Chalcopyrite CIS is a thermodynamically stable phase at room temperature and has a tetragonal structure. In its tetragonal unit cell, both $\mathrm{Cu}$ and In atoms occupy the cation sublattice positions orderly. Zinc blende and wurtzite CIS are metastable at room temperature. When the chalcopyrite CIS is heated to its phase-transition temperature, the two metallic atoms in the tetragonal unit cell become disordered in the cation sites, the tetragonal cell would change into a cubic cell and therefore zinc blende is formed. For the wurtzite phase, sulphur ions are hexagonally close-packed, presenting a nearly fixed structure and the two metallic cations occupy the tetrahedral interstices of

\footnotetext{
${ }^{a}$ State Key Laboratory of Rare Earth Resource Utilization, Changchun Institute of Applied Chemistry, Chinese Academy of Sciences, Changchun, Jilin 130022, PR China. E-mail: cwang@ciac.ac.cn; Fax: +86431 85698041; Tel: +86 43185262770

${ }^{b}$ School of Materials Science and Engineering, Hebei University of Technology, Tianjin 300130, China

${ }^{c}$ Chinese Academy of Sciences, Beijing 100049, PR China

${ }^{d}$ Department of Mechanical Engineering, University of South Carolina, 300 Main Street, Columbia, SC 29208, USA. E-mail: chenfa@cec.sc.edu; Tel: +18037774875 $\dagger$ Electronic supplementary information (ESI) available: Fig. S1 XRD patterns and SEM images of the as-prepared CIS with different volumes of HCl; Fig. S2 nitrogen adsorption-desorption isotherms of chalcopyrite and wurtzite CIS; Fig. S3 the UV-vis absorption spectra of the chalcopyrite and wurtzite CIS. See DOI: $10.1039 / \mathrm{c} 4 \mathrm{ce} 00893 \mathrm{f}$
}

the sulphur framework randomly with the same occupation possibility to meet the charge balance on the whole..$^{7-9}$

The synthesis of chalcopyrite CIS nanoparticles with narrow size distribution and uniform morphology has been extensively pursued. Various morphologies such as nanowires, nanorods, nanobottles, hollow nanospheres and hierarchical microarchitectures ${ }^{10-14}$ have been prepared by a sol process, solvo/hydrothermal procedure, or single-source pyrolysis. ${ }^{15-19}$ Even though there are two main reasons that arouse interest in the study of a new phase of CIS: one is that the two metastable wurtzite and zinc blende CIS phases are considered as counterparts of breaking away from their natural preferences. Therefore, controllable synthesis of metastable materials can enrich the crystallography. ${ }^{20}$ The other is random distribution of the $\mathrm{Cu}$ and In atoms over the cation sites in the wurtzite and zinc blende CIS, which allows flexibility of the stoichiometry and adjustment of the Fermi energy over a wide range. ${ }^{8}$ This is of great significance in the exploration of structure-determined properties and fabrication of the device.

It was not until Lu's group successfully synthesized zinc blende and wurtzite CIS nanoparticles that a thriving number of studies appeared on the new phase CIS. ${ }^{7,9,21-25}$ Wurtzite or zinc blende CIS products with the morphologies of nanoparticles, nanorods, nanodisks, and nanoribbons have been prepared. ${ }^{11,21,24,25}$ The phases of the products can be controlled by means of tailoring solvents, ligand species, sulphur sources, etc. ${ }^{26-28}$ An assumption that the phases of CIS nanocrystals were determined by the growth rate of the nanoparticles was put forward. ${ }^{29}$ The strong bonds between the metallic monomers and ligand molecules and/or large steric bonds of the ligand molecules decreased the growth rate, which resulted in obtaining the thermodynamically stable chalcopyrite phase CIS; otherwise resulting in obtaining the 
kinetically stable wurtzite or zinc blende phase CIS. A clear understanding of the observed effects of the reaction conditions on the phase determination, however, is still lacking.

CIS nanocrystals are widely used in photovoltaic device and photocatalysis because of the high solar energy power conversion efficiency. The factors, including morphology, particle size, crystal orientation and lattice defects that may influence the optoelectronic performance and stability of CIS nanocrystals have been studied. ${ }^{5,26,28,30}$ For comparison of the properties between common chalcopyrite and novel wurtzite/zinc blende CIS, however, there are few reports.

\section{Experimental}

All chemicals were of analytical grade and purchased from Chinese domestic suppliers. Ultra-pure water with resistivity larger than 18.0 $\mathrm{M} \Omega$ was produced from an Ultrapure Water System (Purifier).

\subsection{Synthesis of CIS nanospheres}

In a typical synthesis of chalcopyrite CIS nanospheres, a transparent solution containing $0.25 \mathrm{mmol}$ indium nitrate hydrate $\left(\mathrm{In}\left(\mathrm{NO}_{3}\right)_{3}\right)$ and $1.25 \mathrm{mmol}$ thiourea $(\mathrm{Tu})$ dissolved in $9.0 \mathrm{~mL}$ ethylene glycol (EG) was added to a $25 \mathrm{~mL}$ beaker under constant electromagnetic stirring. Then $0.15 \mathrm{~mL}$ saturated hydrochloric acid $(\mathrm{HCl}, 38 \mathrm{wt} . \%)$ and $0.25 \mathrm{mmol}$ cuprous iodide (CuI) were added to this solution under ultrasonication. After adding $0.5 \mathrm{~g}$ polyvinyl pyrrolidone (PVP-K30, $M_{\mathrm{W}} \approx 50000$ ) to the beaker, the mixture was heated to $80{ }^{\circ} \mathrm{C}$ and kept at this temperature for $5.0 \mathrm{~min}$ to allow dissolution of the precipitate. The light yellow solution was then transferred into a $25 \mathrm{~mL}$ Teflon-lined stainless autoclave, sealed and maintained at $190{ }^{\circ} \mathrm{C}$ for $12 \mathrm{~h}$ in an oven. After the reaction, the autoclave was cooled down naturally to room temperature. The as-obtained product was collected through centrifugation, washed several times with ultra-pure water and ethanol and finally dried in a vacuum oven at $60{ }^{\circ} \mathrm{C}$ for $24 \mathrm{~h}$.

The synthesis of wurtzite CIS nanospheres was similar to the above synthetic process except for using indium chloride $\left(\mathrm{InCl}_{3}, 0.25 \mathrm{mmol}\right)$ as In source. A systematic study of the effect of the anions on the phases of CIS was also carried out by varying the molar ratio of $\mathrm{In}\left(\mathrm{NO}_{3}\right)_{3}$ to $\mathrm{InCl}_{3}$ (abbreviated as $R_{\mathrm{N} / \mathrm{C}}$ ) while keeping the total amount of $\mathrm{In}^{3+}$ at $0.25 \mathrm{mmol}$.

\subsection{Characterization}

Powder X-ray diffraction (XRD) measurements were performed on a Bruker $\mathrm{D} 8$ Focus diffractometer with $\mathrm{Cu} \mathrm{K} \alpha$ radiation and a Lynx Eye detector at a scanning rate of $2^{\circ} \mathrm{min}^{-1}$. Field emission scanning electron microscopy (FESEM) images and scanning electron microscopy with an energy dispersive X-ray analytical system (SEM-EDX) were taken using a Hitachi S-4800 scanning electron microscope. Transmission electron microscopy (TEM) images were taken using an FEI Tecnai F20 transmission electron microscope operated at an accelerating voltage of $200 \mathrm{kV}$. The nitrogen adsorption-desorption isotherm was obtained on Micromeritics' ASAP 2020 Accelerated Surface Area and Porosimetry analyzer (BET). The UV-vis spectra were recorded using a Varian Cary 50 Conc UV-Visible spectrophotometer.

\subsection{Photocatalytic measurements}

For the photocatalytic measurement, $10 \mathrm{mg}$ of CIS nanospheres was completely dispersed into $50 \mathrm{~mL}$ of $\mathrm{RhB}$ aqueous solution $(0.01 \mathrm{mM})$. The sample was firstly magnetically stirred in the dark for $3 \mathrm{~h}$ to ensure absorption equilibrium of RhB onto the surface of CIS nanospheres. A $500 \mathrm{~W}$ xenon lamp equipped with a UV-cutoff filter (providing visible light with $\geq 400 \mathrm{~nm}$ ) was used as a visible-light source. After given time intervals, $3 \mathrm{~mL}$ solution were taken out and centrifuged to remove the photocatalyst. The RhB concentration in the irradiated solution was monitored by measuring the absorption intensity of the supernatant at $553 \mathrm{~nm}$. The degradation degree was evaluated using $C / C_{0} \times 100 \%$, where $C_{0}$ and $C$ represent the absorbance of $\mathrm{RhB}$ solution before and after irradiation, respectively.

\section{Results and discussion}

\subsection{Characterization results}

A representative SEM image of the as-prepared CIS nanospheres is shown in Fig. 1a indicating the well-ordered, hexagonal close-packed CIS layer arrays by a direct self-assembly of CIS nanospheres. However, cracks and other imperfections can hardly be avoided due to evaporation of the solvent. A close-up observation of the nanospheres in Fig. 1b reveals that the product consists of relatively uniform CIS nanospheres with an average size of $200 \mathrm{~nm}$. Actually, the CIS spheres exhibit a hierarchical structure composed of nanoflakes with a thickness of about $5 \mathrm{~nm}$. The nanoflakes are interconnected with each other forming flower-like nanospheres. This result

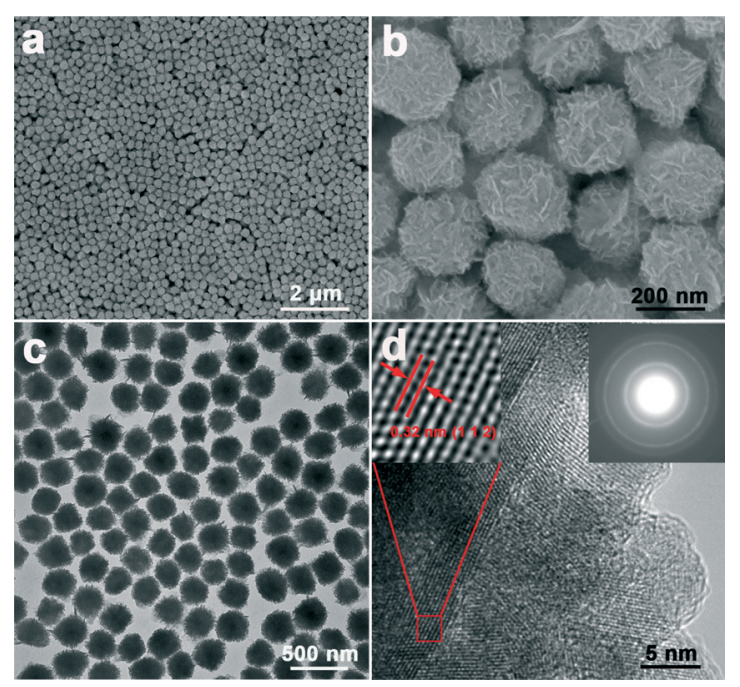

Fig. 1 SEM ( $a$ and b), TEM (c), HRTEM ( $d$ and left inset) and SAED (right inset of d) images of the as-prepared CIS nanospheres. 
is also confirmed by TEM characterization shown in Fig. 1c. It can be observed that the interior core of the most nanospheres is much darker than the other parts of the particle due to the high concentration of $\mathrm{Cu}$, which is similar to the CIS nanoparticles reported previously via solvothermal methods and considered to be stemming from the growth process of CIS. ${ }^{7}$ High-resolution TEM (HRTEM) was used to study the detailed crystalline structures of nanospheres. The clear lattice fringes of the nanoflakes with a lattice of $3.2 \AA$ correspond to the spacing for the (112) planes of chalcopyrite CIS (Fig. 1d and left inset). In addition, the diffraction rings in the selected area electronic diffraction (SAED) pattern of the nanospheres indicate that the CIS nanospheres composed of nanoflakes are polycrystalline (right inset of Fig. 1d).

The phase purity of the product was characterized by powder XRD as shown in Fig. 2a. The as-prepared products are pure chalcopyrite phase CIS with good crystallinity (JCPDS card no. 85-1575). No obvious impurities, such as CuS or $\operatorname{In}_{2} S_{3}$, were found from the XRD pattern. The EDS result of the nanospheres verifies the presence of $\mathrm{Cu}$, In and S elements (Fig. 2b) and their atomic ratio is about 1.1:1:2.

When $\mathrm{InCl}_{3}$ was selected as indium precursor, wurtzite CIS nanospheres were yielded from the reaction system. We failed to find any standard wurtzite phase for CIS in the JCPDS card database, the crystal information of wurtzite CIS
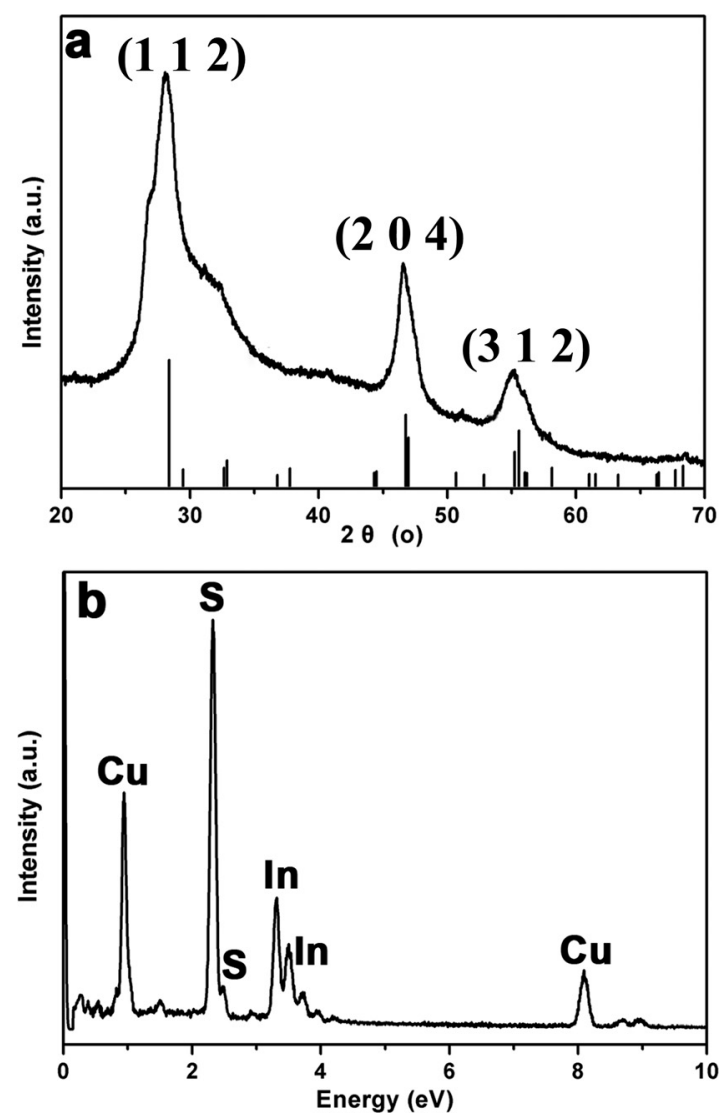

Fig. 2 XRD pattern (a) and EDX spectrum (b) of the as-prepared CIS nanospheres. The vertical lines in (a) indicate the peak positions for the standard chalcopyrite phase CIS (JCPDF no. 85-1575). was obtained by replacing $\mathrm{Zn}^{2+}$ sites by a lower valence $\mathrm{Cu}^{+}$ and a higher valence $\operatorname{~In~}^{3+}$ equally in wurtzite $\mathrm{ZnS}$ while the whole symmetry in the crystal remained unchanged. Such simulation was previously deployed in Pan's report. ${ }^{9}$ Then the XRD pattern of wurtzite CIS can be easily simulated using a Mercury 1.4.1. software (The Cambridge Crystallographic Data Centre). As shown in Fig. 3a, the experimental pattern of the products obtained by adding $\mathrm{InCl}_{3}$ instead of $\operatorname{In}\left(\mathrm{NO}_{3}\right)_{3}$ matches well the simulated one of the wurtzite structure ( $a=4.083 \AA, c=6.727 \AA$ ). The SEM image in Fig. 3b indicates that the dominant morphology of the as-prepared wurtzite CIS was a nanosphere with an average diameter of about $400 \mathrm{~nm}$, accompanied by nanoflowers.

\subsection{Influence of the reaction parameters and growth mechanism}

Many studies have reported that the phase control of ternary I-III-VI ${ }_{2}$ was dependent on the reaction solvents or surfactants. In this system, it was interesting that the phases of as-prepared CIS nanoparticles were strongly influenced by the category of the anion of indium precursor. To study the effects of anions on the phase of CIS nanospheres, $R_{\mathrm{N} / \mathrm{C}}$ was varied while keeping the total amount of $\operatorname{~In~}^{3+}$ at $0.25 \mathrm{mmol}$. Generally, the phases of the CIS nanospheres changed from wurtzite to chalcopyrite gradually with $R_{\mathrm{N} / \mathrm{C}}$ increasing. When $R_{\mathrm{N} / \mathrm{C}}$ was 0.5 , wurtzite and chalcopyrite phases CIS coexisted in the final products according to the XRD pattern (Fig. 4a). The diffraction peaks from the products can be indexed to the wurtzite phase (Fig. 4a). However, some of the diffraction peaks, marked with red squares in Fig. 4a, have different intensities with the simulated wurtzite phase or even don't belong to the wurtzite phase. These diffraction peaks could be attributed to the chalcopyrite CIS, suggesting the existence of chalcopyrite CIS in the products. The morphology of the products was nanoflowers with a diameter of about $500 \mathrm{~nm}$. The nanoflowers were composed of hexagonal plates interconnected together as shown in Fig. $4 \mathrm{~b}$. Further increasing $R_{\mathrm{N} / \mathrm{C}}$ to 2 , the wurtzite phase tended to disappear and changed into chalcopyrite CIS as evidenced from the XRD pattern (Fig. 4c). Unlike the chalcopyrite phase CIS (Fig. 1a and b), the morphology of the products by adding a mixture of indium sources was shaped as a flying saucer (Fig. 4d).

The role of inorganic anions in controlling the phase of nanoparticles has been studied in a previous work.

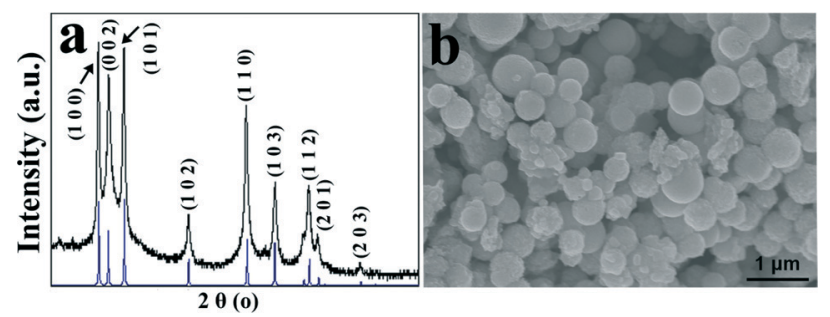

Fig. 3 XRD patterns (a) and SEM images (b) of the as-prepared samples using $\mathrm{InCl}_{3}$ as indium precursor. The blue line at the bottom of (a) is the simulated diffraction patterns of wurtzite phase CIS. 


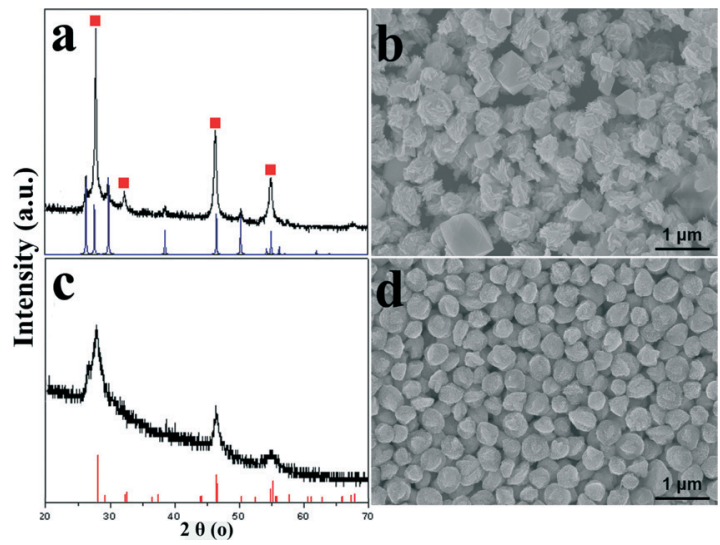

Fig. 4 XRD patterns and SEM images of the as-prepared samples with different $R_{\mathrm{N} / \mathrm{C}}$ : XRD pattern (a) and SEM image (b) of $R_{\mathrm{N} / \mathrm{C}}=0.5, \mathrm{XRD}$ pattern (c) and SEM image (d) of $R_{\mathrm{N} / \mathrm{C}}=2$. The simulated diffraction patterns of wurtzite phase CIS (in blue) and the standard JCPDF data for chalcopyrite CIS (in red) are also given. The peaks signified by red squares in (a) belong to the chalcopyrite phase CIS.

Tai's group found that halide ions such as $\mathrm{Cl}^{-}, \mathrm{Br}^{-}$and $\mathrm{I}^{-}$can induce phase transformation of $\mathrm{CdS}$ from zinc blende to wurtzite. ${ }^{31}$ The phenomenon of phase control of CdS nanoparticles by anions was explained with respect to the adsorption behavior of halide ions on nanostructure surfaces, which can affect the surface free energies of CdS nanostructure and then induce phase transformation of zinc blende (face centered cubic) to wurtzite (hexagonal close packed). Although we got similar results that the phase of CIS nanoparticles depended on the adding of anions, the mechanism, which will be discussed in detail in a later part, of anions induced phase transformation in the reaction system does not agree with them.

The effect of the volume of $\mathrm{HCl}$ (38 wt.\%) on the chalcopyrite CIS nanosphere was investigated. By increasing the volume of $\mathrm{HCl}$ from 0 to $0.15 \mathrm{ml}$, the sizes of the CIS nanoplates assembling into spheres changed from about 10 to $100 \mathrm{~nm}$ while the phase of the products was only chalcopyrite (Fig. S1a-c $\dagger$ ). Without $\mathrm{HCl}$, the product was mainly aggregated nanoplates with a primary particle size of around $10 \mathrm{~nm}$ (Fig. S1d $\dagger$ ). Increasing the volume of $\mathrm{HCl}$ to $0.05 \mathrm{ml}$, CIS nanospheres aggregated by nanoplates were formed and the resultant nanoplates became larger (Fig. S1e $\dagger$ ). At an even higher volume of $0.1 \mathrm{ml} \mathrm{HCl}$, the nanoplates that assembled to form the nanospheres became thicker and larger, and the final morphology was almost the same as that when adding the optimum volume of $0.15 \mathrm{ml} \mathrm{HCl}$ (Fig. S1f $\dagger$ ). In our previous paper, the major role of $\mathrm{HCl}$ in a reaction system containing the substance of Tu has been studied. ${ }^{32}$ When Tu was used as $\mathrm{S}$ precursor for the synthesis of $\mathrm{Ag}_{2} \mathrm{~S}$ nanocrystals, the existence of $\mathrm{H}^{+}$yielded by $\mathrm{HCl}$ suppressed the decomposition of $\mathrm{Tu}$ into $\mathrm{S}^{2-}$ and further decreased the nucleation and growth rates of $\mathrm{Ag}_{2} \mathrm{~S}$ nanoparticles. For the synthesis of CIS nanosphere reported here, with a similar method of reacting Tu and metal ions into chalcogenide nanoparticles, the effects of $\mathrm{HCl}$ as mentioned above is also applicable. The increase of the amount of $\mathrm{HCl}$ could slow down the formation of a CIS nucleus, which is believed to favor the formation of larger nanoplates in our synthesis. According to the results of varying the volume of $\mathrm{HCl}$ described above, one can conclude that $\mathrm{HCl}$ was not the decisive factor in the phase control of as-prepared CIS nanocrystals.

To clarify the growth process and phase-controlled factors in our system, samples of both chalcopyrite and wurtzite were picked from their reaction systems at different reaction intervals of $30 \mathrm{~min}, 1 \mathrm{~h}$ and $3 \mathrm{~h}$. As shown in Fig. 5 and 6, the integration of XRD patterns and the corresponding SEM images of different intermediate samples clearly reveal the growth process. At the initial stage $(30 \mathrm{~min})$, there were no precipitates produced in either the chalcopyrite phase or the wurtzite phase reaction system. However, the colour of

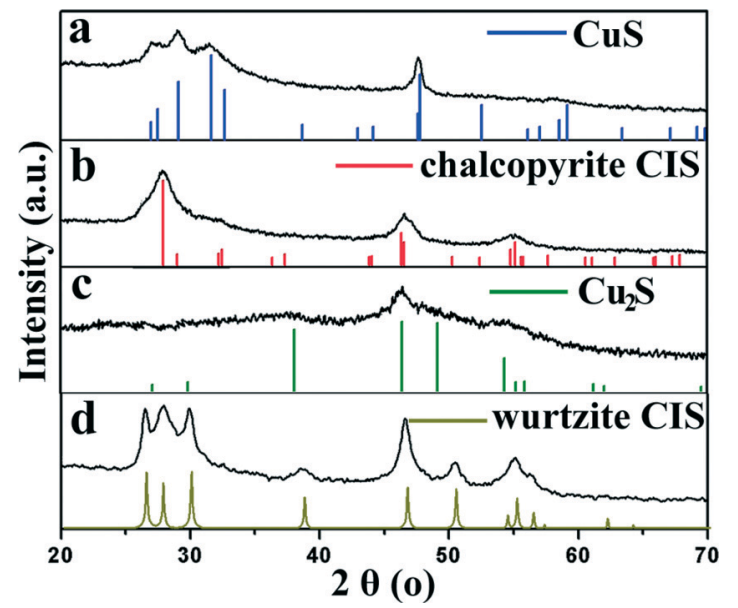

Fig. 5 XRD patterns of intermediate products prepared with different In sources for various reaction times. $\ln \left(\mathrm{NO}_{3}\right)_{3}$ as In source for chalcopyrite $\mathrm{CIS}: 1 \mathrm{~h}$ (a), $3 \mathrm{~h}$ (b). $\mathrm{InCl}_{3}$ as In source for wurtzite $\mathrm{CIS}: 1 \mathrm{~h}$ (c), $3 \mathrm{~h}$ (d). The reference patterns of $\mathrm{CuS}_{1} \mathrm{Cu}_{2} \mathrm{~S}$ and chalcopyrite phase $\mathrm{CIS}$ from JCPDS cards are shown, along with a simulated diffraction pattern of the wurtzite phase CIS.

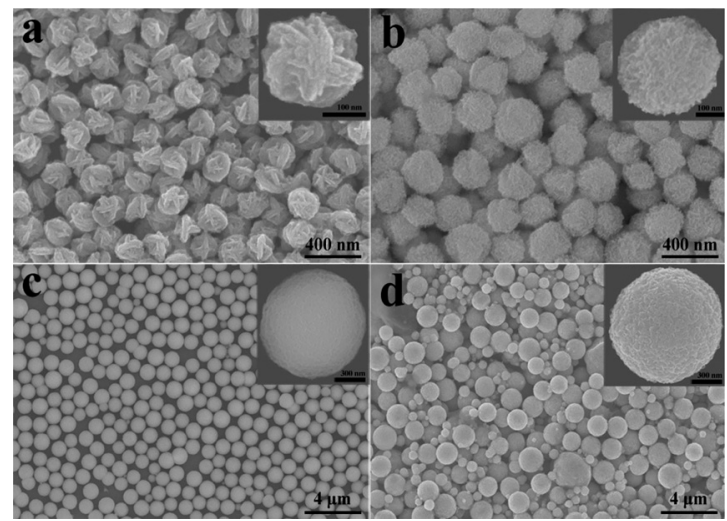

Fig. 6 SEM images of intermediate products prepared with different In sources for various reaction times. $\ln \left(\mathrm{NO}_{3}\right)_{3}$ as In source for chalcopyrite $\mathrm{CIS}: 1 \mathrm{~h} \mathrm{(a),} 3 \mathrm{~h}$ (b). $\mathrm{InCl}_{3}$ as In source for wurtzite $\mathrm{CIS}: 1 \mathrm{~h}$ (c), $3 \mathrm{~h}$ (d). The insets in (a), (b), (c) and (d) are high-resolution SEM images of the products. 
the clear reaction solution in the chalcopyrite phase system changed from colourless to blue, which means $\mathrm{Cu}(\mathrm{I})$ source has been oxidated into $\mathrm{Cu}(\mathrm{II})$. For the wurtzite phase reaction system, the solution in the autoclave maintained colorless. When the reaction time increased to $1 \mathrm{~h}$, the primary product of the chalcopyrite phase system had an irregular spherical architecture comprised of small nanoplates (Fig. 6a), and the XRD pattern was apparently composed of peaks corresponding to CuS (JCPDS card no. 06-0464) (Fig. 5a). In the case of a wurtzite phase system, the product was regular spheres which had a wide size distribution between several tens of nanometers and more than one micrometer (Fig. 6c). The spheres with smooth surfaces were $\mathrm{Cu}_{2} \mathrm{~S}$ phase (JCPDS card no. 26-1116) instead of CuS as indicated in the XRD pattern of Fig. 5c. As the reaction proceeded for $3 \mathrm{~h}$, the obtained product of chalcopyrite phase system grew to nanospheres constructed by loosely packed plates with an average diameter of $200 \mathrm{~nm}$ (Fig. 6b). The XRD pattern investigation shown in Fig. 5b indicates that the sample was pure chalcopyrite CIS, however, the diffraction peaks were broader than those of the reaction for $12 \mathrm{~h}$ due to poor crystallinity. On the other hand, $\mathrm{Cu}_{2} \mathrm{~S}$ in the wurtzite phase system changed into wurtzite CIS which could be proven by the XRD pattern (Fig. $5 \mathrm{~d}$ ) and the morphology was nanospheres aggregated by nanoplates closely (Fig. 6d) which was similar to that of the reaction for $12 \mathrm{~h}$ (Fig. 2b). Hence, the evolution of chalcopyrite and wurtzite CIS nanospheres from the in situ formed $\mathrm{CuS}$ and $\mathrm{Cu}_{2} \mathrm{~S}$, respectively, as intermediate templates was clearly demonstrated by the combined XRD patterns and SEM images.

A reasonable growth mechanism of precursor-determined CIS nanoparticles is proposed on the basis of the above experimental evidence. The growth process of as-prepared CIS nanoparticles can be separated into two steps: nucleation of $\mathrm{CuS}$ or $\mathrm{Cu}_{2} \mathrm{~S}$ and growth of the CIS main body, and this process is also similar to that of $\mathrm{Cu}_{2} \mathrm{~S}$-CIS heterostructures and homogeneous CIS nanoparticles. ${ }^{8,11,14}$ In the first step, the characterization of XRD patterns and SEM images shown in Fig. 5 and 6 provided a direct evidence that the formation of $\mathrm{CuS}$ or $\mathrm{Cu}_{2} \mathrm{~S}$ nucleus was dependent on the addition of In precursors in the reaction system. In the case of adding In $\left(\mathrm{NO}_{3}\right)_{3}$ as In precursor, $\mathrm{NO}_{3}{ }^{-}$could easily oxidize the $\mathrm{Cu}^{+}$ precursor into $\mathrm{Cu}^{2+}$ under acid solution. In the high-boiling point and viscous solvent of EG with dispersed PVP, the Tu decomposed to $\mathrm{S}^{2-}$ gradually and then reacted with $\mathrm{Cu}^{2+}$ to form CuS nanoflowers (Fig. 5a and 6a), which warranted the homogeneous morphology of the nanospheres for the final products. Without $\mathrm{HCl}$, which was the supplier of $\mathrm{H}^{+}, \mathrm{NO}_{3}{ }^{-}$ could also oxidize the $\mathrm{Cu}^{+}$precursor into $\mathrm{Cu}^{2+}$ by cooperating with EG at high-temperature conditions (Fig. S1a $\dagger$ ). When $\mathrm{InCl}_{3}$ was added into the reaction system as the In precursor, no oxidants like $\mathrm{NO}_{3}{ }^{-}$were introduced so that the oxidation of $\mathrm{Cu}^{+}$precursor was avoided and the $\mathrm{Cu}_{2} \mathrm{~S}$ intermediate was formed (Fig. 5c and 6c).

With a prolonged reaction, a phase conversion of $\mathrm{CuS}$ or $\mathrm{Cu}_{2} \mathrm{~S}$ into CIS would happen and there are several interesting points about the conversion mechanisms. First, the hexagonal $\mathrm{CuS}$ consists of stacked $\mathrm{CuS}_{4}-\mathrm{CuS}_{3}-\mathrm{CuS}_{4}$ layers along the $c$ axis, ${ }^{29}$ whereas the chalcopyrite CIS contains equivalent sites for $\mathrm{Cu}$ and In atoms which are coordinated with four S atoms to form $\mathrm{CuS}_{4}$ or $\mathrm{InS}_{4}$ tetrahedron. ${ }^{14}$ The structure similarities of CuS and chalcopyrite CIS make the phase conversion from CuS to chalcopyrite CIS manageable with a low energy barrier. Second, $\mathrm{Cu}_{2} \mathrm{~S}$ and wurtzite CIS both have a hexagonal structure and nearly share the identical packing of S sublattices. For that reason, the $\mathrm{S}$ sublattices do not need to move while half of the $\mathrm{Cu}^{+}$ions are required to move out of the $\mathrm{Cu}_{2} \mathrm{~S}$ phase and half of the remaining $\mathrm{Cu}^{+}$ ions are replaced by $\mathrm{In}^{3+}$ ions. Then both $\mathrm{Cu}^{+}$and $\mathrm{In}^{3+}$ ions randomly distribute among the tetrahedral sites formed by S sublattices, resulting in the wurtzite CIS phase. According to the analysis above, the following growth processes of chalcopyrite CIS and wurtzite CIS are similar. The intermediate $\mathrm{CuS}$ or $\mathrm{Cu}_{2} \mathrm{~S}$ serves as the self-sacrificed template reacting with the remaining $\mathrm{In}^{3+}$ to form CIS continuously. The differences between the two phase transformations are that $\mathrm{Cu}^{2+}$ ions in $\mathrm{CuS}$ could be reduced to $\mathrm{Cu}^{+}$by EG previously before reacting with $\mathrm{In}^{3+}$ ions. In these processes, the copper ions in both $\mathrm{CuS}$ and $\mathrm{Cu}_{2} \mathrm{~S}$ have relatively high mobility at the reaction temperature $\left(190{ }^{\circ} \mathrm{C}\right)$, which can speed up exchanges with In ions and chemical transformation to CIS. For chalcopyrite CIS, the size of the hierarchical nanospheres is similar to that of CuS templates, however the morphologies transfer from CuS nanoflowers to CIS nanospheres as shown in Fig $6 \mathrm{a}$ and $\mathrm{b}$. That is because copper ions could flow out of the lattice of the CuS and infiltrate the newly formed structure when $\mathrm{In}^{3+}$ begins to coordinate with the sulfur atoms exposed on the surface of CuS. ${ }^{7}$ On the contrary, the wurtzite CIS nanospheres achieve a wider size distribution and rougher surface as compared to the $\mathrm{Cu}_{2} \mathrm{~S}$ templates. This suggests that the formation of wurtzite CIS nanospheres is based on the consumption of $\mathrm{Cu}_{2} \mathrm{~S}$ to form CIS nuclei on the surfaces of $\mathrm{Cu}_{2} \mathrm{~S}$ nanospheres, and then $\mathrm{In}^{3+}$ ions diffusing into the remaining smaller $\mathrm{Cu}_{2} \mathrm{~S}$ nanospheres to form homogeneous wurtzite CIS.

\subsection{Textural and photocatalytic performances}

Nitrogen physisorption studies of both the chalcopyrite and wurtzite CIS nanospheres were conducted to determine the textural properties (specific surface areas, pore volumes and pore diameters). A type IV isotherm with $\mathrm{H} 3$ hysteresis was observed for both samples as shown in Fig. S2, $\dagger$ which is typical of mesoporous materials. ${ }^{33}$ The specific surface areas of the chalcopyrite and wurtzite CIS nanospheres were calculated to be 67 and $36 \mathrm{~m}^{2} \mathrm{~g}^{-1}$, respectively, by the Brunauer-Emmett-Teller (BET) equation. The insets of Fig. S2a and $\mathrm{b} \dagger$ show the pore size distributions estimated using the Barrett-Joyner-Halenda (BJH) equation to the desorption isotherm. For the chalcopyrite CIS, most of the pores are in the range of 3 to $10 \mathrm{~nm}$ with a maximum at $3.6 \mathrm{~nm}$ (inset of Fig. S2a†). For the wurtzite one, a number of pores were less than $3.2 \mathrm{~nm}$, which is a little smaller than those of chalcopyrite CIS. 
The UV-vis absorption spectra of chalcopyrite and wurtzite CIS nanospheres dispersed in ethanol were taken and are displayed in Fig. S3.† Both samples show strong absorption over the entire visible light spectrum and significant absorption into the near-infrared region. The broad absorption feature to $1200 \mathrm{~nm}$ is particularly desirable for solar cell applications as a wide range of the solar spectrum can be utilized. Furthermore, the bandgap energies can be estimated by related curves of $(\alpha h v)^{2}$ versus photon energy plotted in the inset of Fig. S3. $\uparrow$ The bandgap energy of $1.70 \mathrm{eV}$ was found for the chalcopyrite CIS nanospheres, which is slightly higher than that of $1.62 \mathrm{eV}$ for the wurtzite phase. It is well-known that the band structure of a semiconductor is strongly dependent on the symmetry of a crystal structure. ${ }^{23}$ Hence, the observed optical behavior is consistent with the theoretical prediction that disordering of cations in the chalcopyrite structure (can be considered as wurtzite phase) induces a bandgap decrease.

The photocatalytic activities of as-prepared chalcopyrite and wurtzite CIS nanospheres were evaluated by analyzing the degradation of $\mathrm{RhB}(10 \mathrm{mM})$ in an aqueous solution under a $500 \mathrm{~W}$ Xe lamp for $2 \mathrm{~h}$ (Fig. 7). Without CIS photocatalysts, less than $10 \% \mathrm{RhB}$ was degraded after $2 \mathrm{~h}$ irradiation. Fig. 7a shows the temporal evolution of the absorption spectra of the RhB solution in the presence of chalcopyrite CIS nanospheres under visible-light irradiation. For comparison, the evolution of the absorption spectra of $\mathrm{RhB}$ under the wurtzite CIS nanospheres photocatalyst was also monitored (Fig. 7b). It has been reported that the photodegradation of $\mathrm{RhB}$ included two competitive processes, $\mathrm{N}$-demethylation and destruction of the conjugated structure. ${ }^{34} \mathrm{~N}$-Demethylation was accompanied by the peak position of its major absorption shifting from $552 \mathrm{~nm}$ to the shorter wavelength, whereas the destruction of the conjugated structure led to a decrease in the intensity of the major absorption peak. In the present case, the RhB concentration was analyzed by checking the characteristic absorption at $552 \mathrm{~nm}$. In both of the chalcopyrite and wurtzite CIS system, as shown in Fig. 7a and b, the absorbance of the major absorption peak at $552 \mathrm{~nm}$ decreased systematically with increasing illumination time and the positions of this peak were not shifted, suggesting that the aromatic rings of $\mathrm{RhB}$ were destroyed instead of $\mathrm{N}$-demethylation. The degradation efficiencies of the RhB dependent on illumination time in the presence of chalcopyrite or wurtzite CIS nanospheres are summarized in Fig. 7c. It was found that the adsorption percentages of RhB over chalcopyrite and wurtzite CIS in the adsorption equilibrium were 70 and $50 \%$, respectively. These results reveal that the two samples exhibit excellent adsorption percentages caused by their micro/mesoporous configuration, and the differences between them could be attributed to the various specific surface areas. During the following photodegradation process, apparently, the photocatalytic activity of the chalcopyrite CIS nanospheres is higher than that of wurtzite CIS. For the chalcopyrite CIS, the characteristic absorption peak of RhB disappears completely within $30 \mathrm{~min}$. On the other
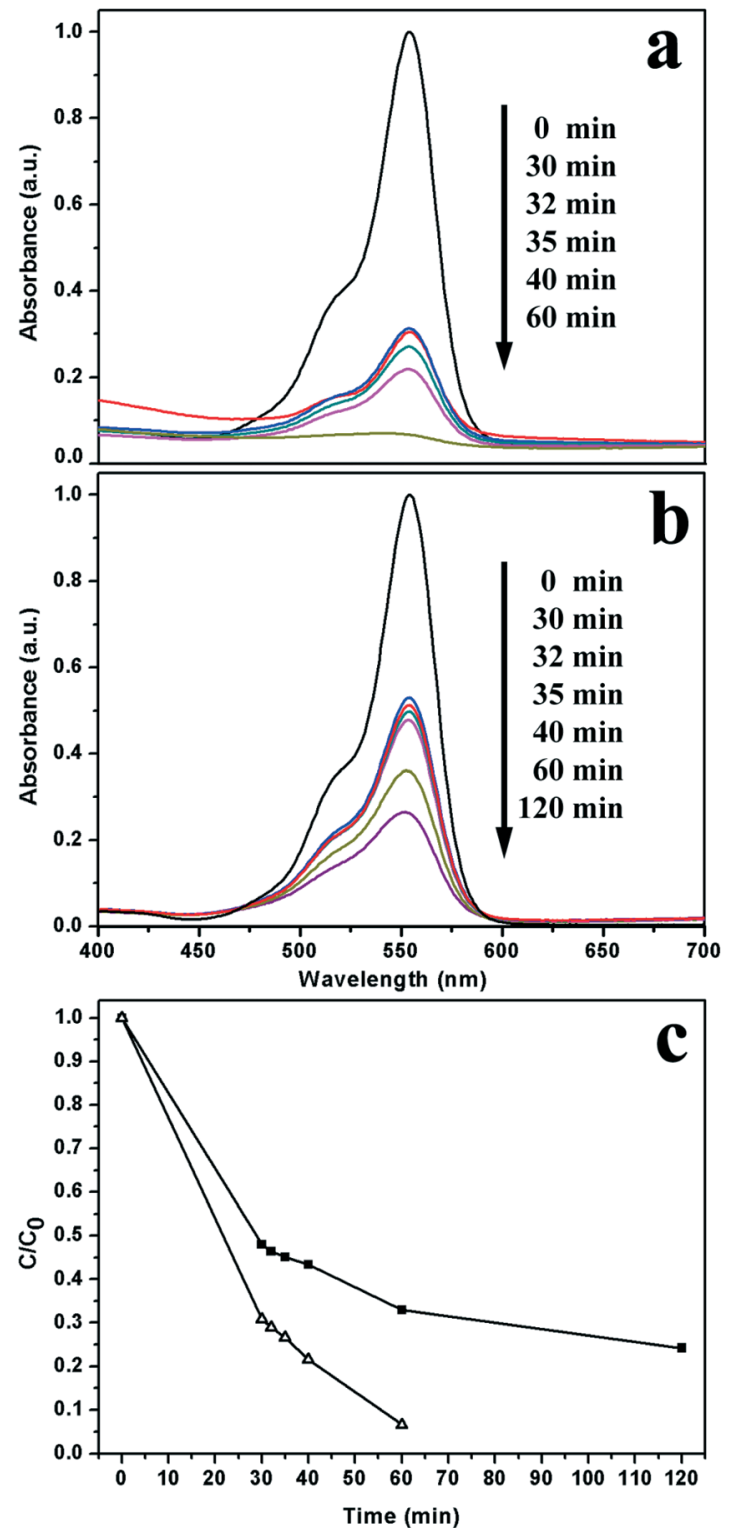

Fig. 7 Temporal evolution of the absorption spectra of aqueous RhB solution in the presence of chalcopyrite phase CIS (a) and wurtzite phase CIS (b) under visible-light irradiation. Photocatalytic degradation over RhB of CIS nanospheres (c). The triangles represent chalcopyrite phase CIS whereas the squares represent wurtzite phase CIS. The initial $30 \mathrm{~min}$ was spent stirring in the dark for the adsorption equilibrium.

hand, the degradation efficiency in the wurtzite CIS system is only $65 \%$ even prolonging the illumination time to $90 \mathrm{~min}$. The results of this study indicate that chalcopyrite CIS more effectively served as a visible-light-responsive catalyst for the degradation of RhB than the wurtzite one. The better photocatalytic ability of chalcopyrite CIS nanospheres may be attributed to the following factors. First, the higher specific surface area and average pore diameter of chalcopyrite CIS nanospheres can generate more active sites for the absorption of RhB molecules. The high absorption capacity is essential for catalytic reactions. Second, the photocatalytic process could accompany the photodecomposition. For the Cu-riched 
chalcopyrite CIS nanospheres, metallic Cu nuclei may be more apt to form during photodecomposition, which would act as electron transference catalysts and then make the chalcopyrite phase products exhibit higher activity in the degradation of RhB.

\section{Conclusions}

In conclusion, we have adopted a solvothermal synthesis approach to make monodisperse chalcopyrite CIS nanospheres using $\operatorname{In}\left(\mathrm{NO}_{3}\right)_{3}$ as In source. By changing In precursor to $\mathrm{InCl}_{3}$, wurtzite CIS nanocrystals were obtained. Using both of $\operatorname{In}\left(\mathrm{NO}_{3}\right)_{3}$ and $\mathrm{InCl}_{3}$ as In sources, mixed chalcopyrite and wurtzite CIS nanoparticles were produced. This phase determination was explained from the perspective of crystal structures of the intermediate and final products. In the case of using $\mathrm{In}\left(\mathrm{NO}_{3}\right)_{3}$ as In source, the intermediate CuS template formed which directed the growth of chalcopyrite CIS due to their similar crystal structures. The intermediate $\mathrm{Cu}_{2} \mathrm{~S}$ template appeared in the reaction system of using $\mathrm{InCl}_{3}$ as In source, which resulted in the formation of thermodynamically metastable wurtzite CIS because the conversion from $\mathrm{Cu}_{2} \mathrm{~S}$ to wurtzite CIS requires little lattice distortion and thus can be realized with a low-energy barrier. An investigation of the photocatalytic activity shows that the chalcopyrite CIS nanospheres are more effective in being utilized as a photocatalyst for RhB degradation under visible-light illumination than the wurtzite phase.

\section{Acknowledgements}

The authors are grateful for financial support from the National Natural Science Foundation of China (NSFC) through the Major Research Plan (91022005), NSFC (21171159), and the Innovative Research Groups (21221061). Fanglin Chen was supported by the HeteroFoaM Center, an Energy Frontier Research Center funded by the US Department of Energy (DoE), Office of Science, Basic Energy Sciences (BESs), under award no. DE-SC0001061.

\section{Notes and references}

1 S. Jeong, B. S. Lee, S. Ahn, K. Yoon, Y. H. Seo, Y. Choi and B. H. Ryu, Energy Environ. Sci., 2012, 5, 7539-7542.

2 Q. Guo, S. J. Kim, M. Kar, W. N. Shafarman, R. W. Birkmire, E. A. Stach, R. Agrawal and H. W. Hillhouse, Nano Lett., 2008, 8, 2982-2987.

3 T. Pons, E. Pic, N. Lequeux, E. Cassette, L. Bezdetnaya, F. Guillemin, F. Marchal and B. Dubertret, ACS Nano, 2010, 4, 2531-2538.

4 J. J. He, W. H. Zhou, J. Guo, M. Li and S. X. Wu, CrystEngComm, 2012, 14, 3638-3644.

5 H. Liu, Z. Jin, W. Wang and J. Li, CrystEngComm, 2011, 13, 7198-7201.

6 B. Tell, J. L. Shay and H. M. Kasper, Phys. Rev. B: Solid State, 1971, 4, 2463-2471.

7 X. Lu, Z. Zhuang, Q. Peng and Y. Li, CrystEngComm, 2011, 13, 4039-4045.
8 M. Kruszynska, H. Borchert, J. R. Parisi and J. Kolny-Olesiak, J. Am. Chem. Soc., 2010, 132, 15976-15986.

9 D. Pan, L. An, Z. Sun, W. Hou, Y. Yang, Z. Yang and Y. Lu, J. Am. Chem. Soc., 2008, 130, 5620-5621.

10 L. Shi, P. Yin, L. Wang and Y. Qian, CrystEngComm, 2012, 14, 7217-7221.

11 S. T. Connor, C. M. Hsu, B. D. Weil, S. Aloni and Y. Cui, J. Am. Chem. Soc., 2009, 131, 4962-4966.

12 S. H. Choi, E. G. Kim and T. Hyeon, J. Am. Chem. Soc., 2006, 128, 2520-2521.

13 A. Zhang, Q. Ma, M. Lu, G. Yu, Y. Zhou and Z. Qiu, Cryst. Growth Des., 2008, 8, 2402-2405.

14 L. Zheng, Y. Xu, Y. Song, C. Wu, M. Zhang and Y. Xie, Inorg. Chem., 2009, 48, 4003-4009.

15 H. Zhong, Y. Zhou, M. Ye, Y. He, J. Ye, C. He, C. Yang and Y. Li, Chem. Mater., 2008, 20, 6434-6443.

16 D. Wang, W. Zheng, C. Hao, Q. Peng and Y. Li, Chem. Commun., 2008, 2556-2558.

17 X. Gou, F. Cheng, Y. Shi, L. Zhang, S. Peng, J. Chen and P. Shen, J. Am. Chem. Soc., 2006, 128, 7222-7229.

18 J. J. Nairn, P. J. Shapiro, B. Twamley, T. Pounds, R. vonWandruszka, T. R. Fletcher, M. Williams, C. Wang and M. G. Norton, Nano Lett., 2006, 6, 1218-1223.

19 S. L. Castro, S. G. Bailey, R. P. Raffaelle, K. K. Banger and A. F. Hepp, Chem. Mater., 2003, 15, 3142-3147.

20 Y. Cui, G. Wang and D. C. Pan, CrystEngComm, 2013, 15, 10459-10463.

21 Q. Li, L. Zhai, C. Zou, X. Huang, L. Zhang, Y. Yang, X. Chen and S. Huang, Nanoscale, 2013, 5, 1638-1648.

22 J. J. Wang, Y. Q. Wang, F. F. Cao, Y. G. Guo and L. J. Wan, J. Am. Chem. Soc., 2010, 132, 12218-12221.

23 Y. Qi, Q. Liu, K. Tang, Z. Liang, Z. Ren and X. Liu, J. Phys. Chem. C, 2009, 113, 3939-3944.

24 B. Koo, R. N. Patel and B. A. Korgel, Chem. Mater., 2009, 21, 1962-1966.

25 S. K. Batabyal, L. Tian, N. Venkatram, W. Ji and J. J. Vittal, J. Phys. Chem. C, 2009, 113, 15037-15042.

26 W. C. Huang, C. H. Tseng, S. H. Chang, H. Y. Tuan, C. C. Chiang, L. M. Lyu and M. H. Huang, Langmuir, 2012, 28, 8496-8501.

27 T. Kuzuya, Y. Hamanaka, K. Itoh, T. Kino, K. Sumiyama, Y. Fukunaka and S. Hirai, J. Colloid Interface Sci., 2012, 388, 137-143.

28 N. Bao, X. Qiu, Y.-H. A. Wang, Z. Zhou, X. Lu, C. A. Grimes and A. Gupta, Chem. Commun., 2011, 47, 9441-9443.

29 K. Nose, Y. Soma, T. Omata and S. Otsuka-Yao-Matsuo, Chem. Mater., 2009, 21, 2607-2613.

30 Y. Kim, S. Ahn, K. Chung, Y. Cho and C. Choi, J. Mater. Chem., 2012, 22, 1516-1520.

31 G. Tai, J. Zhou and W. Guo, Nanotechnology, 2010, 21, 175601-175607.

32 C. Yu, M. Leng, M. Liu, Y. Yu, D. Liu and C. Wang, CrystEngComm, 2012, 14, 3772-3777.

33 K. S. W. Sing, Pure Appl. Chem., 1982, 54, 2201-2218.

34 W. Wang, W. Zhu and H. Xu, J. Phys. Chem. C, 2008, 112, 16754-16758. 